\title{
Malignant germ cell tumours of childhood: new associations of genomic imbalance
}

\author{
RD Palmer, I,2, NA Foster', SL Vowler ${ }^{3}$, I Roberts', CM Thornton ${ }^{4}$, JP Hale ${ }^{5}$, DT Schneider ${ }^{6}$, JC Nicholson ${ }^{2}$ and \\ N Coleman', on behalf of the Children's Cancer and Leukaemia Group (CCLG) \\ 'MRC Cancer Cell Unit, Hutchison/MRC Research Centre, Box 197, Hills Road, Cambridge, CB2 2XZ, UK; '² Department of Paediatric Oncology, \\ Addenbrooke's Hospital, Box 181, Hills Road, Cambridge, CB2 2QQ, UK; ${ }^{3}$ Centre for Applied Medical Statistics, Department of Public Health \& Primary \\ Care, University of Cambridge Forvie Site, Robinson Way, Cambridge, CB2 2SR, UK; ${ }^{4}$ Department of Pathology, Institute of Clinical Science, Royal Group of \\ Hospitals, Grosvenor Road, Belfast, BTI2 6BA, UK; ${ }^{5}$ Department of Paediatric Oncology, Sir James Spence Institute of Child Health, Royal Victoria \\ Infirmary, Queen Victoria Road, Newcastle Upon Tyne, NEI 4LP, UK; ${ }^{6}$ Department of Pediatric Oncology, Heinrich Heine Universität, Moorenstraße 5, \\ 40225, Düsseldorf, Germany
}

Malignant germ cell tumours (MGCTs) of childhood are a rare group of neoplasms that comprise many histological subtypes and arise at numerous different sites. Genomic imbalances have been described in these tumours but, largely because of the paucity of cases reported in the literature, it is unclear how they relate to abnormalities in adult MGCTs and impact on potential systems for classifying GCTs. We have used metaphase-based comparative genomic hybridisation to analyse the largest series of paediatric MGCTs reported to date, representing 34 primary tumours (22 yolk sac tumours (YSTs), I I germinomatous tumours and one metastatic embryonal carcinoma) occurring in children from birth to age 16, including 17 ovarian MGCTs. The large dataset enabled us to undertake statistical analysis, with the aim of identifying associations worthy of further investigation between patterns of genomic imbalance and clinicopathological parameters. The YSTs showed an increased frequency of I $-(P=0.003), 3 p+(P=0.02), 4 q-$ $(P=0.07)$ and $6 q-(P=0.004)$ compared to germinomatous tumours. Gain of $12 p$, which is invariably seen in adult MGCTs, was present in $53 \%$ of primary MGCTs of children aged $5-16$ and was also observed in four of 14 YSTs affecting children less than 5. Two of these cases ( $14 \%$ of MGCTs in children less than 5) showed gain of the I2p I I locus considered to be particularly relevant in adult MGCTs. Gain of $12 p$ showed a significant association with gain of 12q. Conversely, MGCTs without 12p gain displayed a significantly increased frequency of loss on $16 p(P=0.04)$, suggesting that this imbalance may contribute to tumour development in such cases. This data provides new insight into the biology of this under-investigated tumour group and will direct future studies on the significance of specific genetic abnormalities.

British Journal of Cancer (2007) 96, 667-676. doi: I0.1038/sj.bjc.6603602 www.bjcancer.com

Published online 6 February 2007

(c) 2007 Cancer Research UK

Keywords: neoplasms; germ cell; child; gonadal; extragonadal; comparative genomic hybridisation

Germ cell tumours (GCTs) are a complex group of heterogenous tumours that comprise both benign and malignant histologies. Children in the UK under 16 years of age are treated on paediatric childhood cancer treatment schedules, overseen by Children's Cancer and Leukaemia Group (CCLG). Teratomas in children, whether mature or immature, are deemed benign and treated by surgery alone (Palmer et al, 2003). Chemotherapy is reserved for malignant histologies and the rare occurrence of immature teratoma with widespread seeding (typically peritoneal), when it is used in an attempt to reduce further spread and facilitate surgery. These treatment schedules are different from those used

*Correspondence: Dr RD Palmer, MRC Cancer Cell Unit, Hutchison/ MRC Research Centre, Box 197, Hills Road, Cambridge CB2 2XZ, UK; E-mail: rdp@hutchison-mrc.cam.ac.uk

Received 2 October 2006; revised 20 December 2006; accepted 2 January 2007; published online 6 February 2007 in adults, suggesting that GCTs of adult and childhood are likely to differ biologically.

We are investigating the biology of paediatric malignant germ cell tumours (MGCTs), a diverse group presumed to have a common cell of origin, the primordial germ cell. These tumours occur at several different anatomical sites and, unlike their adult counterparts, only $50 \%$ occur in the gonad. The remainder arise in various midline or near-midline sites, presumed to be due to arrested or aberrant migration of the primordial germ cells during foetal development. There is a bimodal age distribution of childhood MGCTs. The MGCT seen in infancy is the yolk sac tumour (YST), which predominantly arises in the testis but does also occur in alternative sites, for example within sacrococcygeal teratomas (SCT). By later childhood, adolescence and early adulthood, MGCTs are seen in a range of sites, including the ovary, brain and mediastinum, and may be of various histological types, especially embryonal carcinoma (EC), choriocarcinoma, YST and germinomatous tumours (including testicular seminoma and ovarian dysgerminoma). 
Particular histologies are reported to show similar patterns of genomic imbalance irrespective of the site in which they occur (Riopel et al, 1998; Perlman et al, 2000; Rickert et al, 2000; Schneider et al, 2002; Schneider et al, 2006), consistent with the hypothesis that they arise from the same progenitor cell. Recently, a new classification system for GCTs was proposed (Oosterhuis and Looijenga, 2005), dividing GCTs into five types. In this classification, early childhood tumours (typically under 5 years of age and almost exclusively teratoma or YST) are referred to as type I tumours, and separated from the remainder of MGCTs that occur in the rest of childhood or throughout the majority of adulthood. Type II tumours represent all histologies except benign ovarian teratoma (type IV), spermatocytic seminoma (type III) and hydatidiform moles (type V). This classification was based upon the epidemiological and biological differences so far determined between GCT histologies. An important factor in this regard is said to be the lack in type I tumours of $12 \mathrm{p}$ gain (other than gain of small, predominantly telomeric regions in some cases). In contrast, gain of $12 p$ is reported to occur in all type II MGCTs (Oosterhuis and Looijenga, 2005).

Genomic copy number imbalances (CNIs) in MGCTs of adulthood have been extensively investigated. Gain of $12 \mathrm{p}$, which is generated by formation of an isochromosome [iso(12p)] in up to $80 \%$ of cases of adult testicular GCTs (TGCTs), appears to be a specific and early cytogenetic event in all histologies in adults (Korn et al, 1996; Kraggerud et al, 2000; Looijenga et al, 2000). Additional karyotypic abnormalities in these tumours include gains on $1,7,8,12,21$, and $\mathrm{X}$, as well as losses on 11,13 and 18 (Summersgill et al, 1998; van Echten et al, 2002), but none is found as consistently as $12 \mathrm{p}$ gain. In contrast, genomic CNIs in childhood MGCTs, whether deemed type I or II, have received comparatively little investigation. There have been several investigations of small numbers of cases, generally as a component of studies that also included teratomas. A wide range of CNIs has been described in childhood MGCTs, including gains on 1q, 2p, 3, 7, 8, 13, 14, 20q, 21 , and $\mathrm{X}$, as well as losses on 1p36, 4q, 6q, 11, 13 and 18; but again none is seen consistently (Mostert et al, 2000; Perlman et al, 2000; Schneider et al, 2002; van Echten et al, 2002; Schneider et al, 2006). In all these studies, comparative genomic hybridisation (CGH) findings were consistent with previous cytogenetic data and with verification studies based on fluorescent in situ hybridisation. Metaphase chromosomes have generally been used for CGH and only limited additional information appears to have been gained in the analysis of childhood MGCTs by using $1 \mathrm{MB}$ CGH arrays (Veltman et al, 2005).

An important reason why it is not possible to identify with confidence which CNIs are important in childhood MGCTs is that data from only 82 samples (where age and CGH profile are presented) of these heterogenous tumours have been reported to date. This lack of information has clinical implications. For example, there is uncertainty concerning whether MGCTs in adolescents should be regarded as being of adult or childhood type and which algorithms are required to inform this decision. We reasoned that a single large study would allow investigation of CNIs in childhood MGCTs in relation to histology and clinicopathological data and enable statistical investigation of associations between CNIs.

We have therefore used metaphase CGH to identify CNIs worthy of further investigation in childhood MGCTs. We deliberately chose cases from patients of 16 and under, in whom paediatric treatment schedules are applied in the UK. We used a large series of 34 paediatric MGCTs, representing the entire Children's Cancer and Leukaemia Group (CCLG) bank of frozen tumours available at the time of the study, together with additional unselected cases made available from European collaboration with Heinrich Heine University, Düsseldorf. This study therefore represents the most comprehensive genomic analysis of this tumour group reported to date. We have identified previously unreported CNI associations of potential significance in the biology of childhood MGCTs and, in particular, have observed that gain of $12 \mathrm{p}$ (including 12p11) is reasonably common in YSTs of children under 5.

\section{MATERIALS AND METHODS}

\section{Tumour samples}

Banked frozen tissue was provided by the CCLG from children 16 years of age or younger. A total of 29 tumours from United Kingdom were treated on the extracranial GC 8901 (1989-2004) study, with three additional specimens made available from the CCLG intracranial germ cell tumour study and two unselected specimens from German GPOH-MAKEI studies. Following Multicentre Research Ethics Committee approval (ref 02/4/071), tumour material was transported to Cambridge from the banking centres across the UK and Germany for analysis. In total, 34 tumours were analysed, each from a different patient. None of the tumours had been included in previous studies. Thirty-three cases were primary tumours, while one was a pulmonary metastasis of an EC of the testis. Nineteen tumours were stage 1 , six stage 2, two stage 3 and seven stage 4 . Two children died (one of disease, one unrelated) and five relapsed (three of whom had stage 1 disease and received no primary chemotherapy), with follow-up ranging from 12 to 144 months in disease-free cases.

Each case was provided with a histological diagnosis following CCLG expert panel review. Patient characteristics are shown in Table 1. All specimens examined in the study initially underwent frozen section analysis, with independent review by three separate histopathologists, two of whom are consultant paediatric histopathologists. This process enabled confirmation of the histopathological diagnosis and the presence of at least $90 \%$ tumour cells in each frozen tissue sample.

\section{DNA isolation}

Sections of tumour were homogenised (PolyTron PT2100) in TRIzol (Invitrogen, Paisley, UK) to preserve nucleic acids. Following the addition of chloroform, DNA was extracted from the interphase/organic phase using ethanol precipitation. The resultant DNA pellets were serially washed with $0.1 \mathrm{M}$ sodium citrate in $10 \%$ ethanol, before resuspension in water $(\mathrm{pH} 8.4)$.

\section{CGH microscopy and analysis}

CGH was performed as described previously (Alazawi et al, 2004) but with modifications. Briefly, $50 \mathrm{ng}$ of tumour DNA and male peripheral blood leucocyte reference DNA were amplified and labelled by two-step degenerate oligonucleotide-primed (DOP) PCR using $6 \mathrm{MW}$ primer (Foster et al, 2005). Test DNA was labelled with biotin-16-dUTP and reference DNA with digoxigenin-11-dUTP (Roche, Lewes, UK). DOP-PCR products were combined with $5 \mu \mathrm{g}$ Cot DNA (Roche, Lewes, UK) to form probes before hybridisation with normal male metaphase spreads (Vysis, Richmond, UK) at $42^{\circ} \mathrm{C}$ for $48 \mathrm{~h}$. Following stringency washes, detection was performed with streptavidin-Cy3 antibody (Amersham Biosciences, Little Chalfont, UK) and anti-digoxigenin-FITC antibody (Roche, Lewes, UK). Chromosomes were counterstained with DAPI and images captured using an Axioplan II fluorescence microscope equipped with filter sets for DAPI, FITC and $\mathrm{Cy} 3$ (Chroma, Rockingham, VT, USA). Images were acquired using SmartCapture 2001 software (Digital Scientific, Cambridge, UK) and analysed using Quips CGH karyotyper (Vysis, Downers Grove, IL, USA).

At least 10 metaphases were analysed for each sample. The thresholds used for detection of loss and gain were 0.8 and 1.2, respectively, based on normal:normal hybridisations using normal gonadal tissue (data not shown). As the same normal male control 
Table I Clinicopathological data for the 34 MGCTs of childhood analysed

\begin{tabular}{|c|c|c|c|c|c|c|c|c|}
\hline Sample & Histology & Histology subtype & Site & Age (years) & Gender & Stage & Outcome & $E S^{a}$ (months) \\
\hline 1 & Germinoma & Pure & Ovary & 12 & Female & I & Alive & 47 \\
\hline 2 & Germinoma & Pure & Ovary & 13 & Female & 3 & Alive & 46 \\
\hline 3 & Germinoma & Pure & Ovary & 14 & Female & 2 & Alive & 40 \\
\hline 4 & Germinoma & Pure & Ovary & 10 & Female & I & Relapse & 16 \\
\hline 5 & Germinoma & Pure & Ovary & 6 & Female & 4 & Alive & 20 \\
\hline 6 & Germinoma & Pure & Ovary & 12 & Female & I & Dead & 27 \\
\hline 7 & Germinoma & Pure & Ovary & 12 & Female & I & Alive & 15 \\
\hline 8 & Germinoma & Pure & Ovary & 13 & Female & I & Relapse & 23 \\
\hline 9 & Germinoma & Pure & Brain & 16 & Male & । & Alive & 144 \\
\hline 10 & Germinoma & Pure & Brain & 10 & Female & I & Dead & 14 \\
\hline | | & Germinoma & Within teratoma & Ovary & 12 & Female & 2 & Alive & 36 \\
\hline 12 & Embryonal carcinoma & Pure & Metastasis $^{b}$ & 15 & Male & 4 & Relapse & 8 \\
\hline 13 & Yolk sac tumour & Pure & Testis & 1 & Male & । & Alive & 51 \\
\hline 14 & Yolk sac tumour & Pure & Testis & 1 & Male & I & Alive & 92 \\
\hline 15 & Yolk sac tumour & Pure & Testis & 0 & Male & I & Alive & 37 \\
\hline 16 & Yolk sac tumour & Pure & Testis & 4 & Male & I & Alive & 30 \\
\hline 17 & Yolk sac tumour & Pure & Testis & I & Male & I & Alive & 14 \\
\hline 18 & Yolk sac tumour & Pure & Testis & 0 & Male & । & Alive & 12 \\
\hline 19 & Yolk sac tumour & Pure & Testis & 2 & Male & । & Alive & 44 \\
\hline 20 & Yolk sac tumour & Pure & Ovary & 14 & Female & 4 & Alive & 78 \\
\hline 21 & Yolk sac tumour & Pure & Ovary & 13 & Female & 2 & Alive & 58 \\
\hline 22 & Yolk sac tumour & Pure & Ovary & 12 & Female & I & Alive & 28 \\
\hline 23 & Yolk sac tumour & Pure & Ovary & 12 & Female & I & Alive & 69 \\
\hline 24 & Yolk sac tumour & Pure & Ovary ${ }^{c}$ & 9 & Female & 2 & Alive & 93 \\
\hline 25 & Yolk sac tumour & Pure & Ovary & 14 & Female & I & Relapse & 2 \\
\hline 26 & Yolk sac tumour & Pure & Ovary & 13 & Female & 3 & Alive & 72 \\
\hline 27 & Yolk sac tumour & Within teratoma & SCT & 2 & Female & 4 & Alive & 55 \\
\hline 28 & Yolk sac tumour & Within teratoma & $\mathrm{SCT}$ & 3 & Female & 4 & Alive & 21 \\
\hline 29 & Yolk sac tumour & Within teratoma & $\mathrm{SCT}$ & 0 & Female & 4 & Alive & 42 \\
\hline 30 & Yolk sac tumour & Within teratoma & $\mathrm{SCT}$ & 1 & Male & 4 & Alive & 28 \\
\hline 31 & Yolk sac tumour & Within teratoma & SCT & 1 & Male & I & Alive & 54 \\
\hline 32 & Yolk sac tumour & Within teratoma & Brain & 12 & Male & I & Alive & 136 \\
\hline 33 & Yolk sac tumour & Pure & Ovary & 0 & Female & 2 & Relapse & 4 \\
\hline 34 & Yolk sac tumour & Pure & Vagina & 1 & Female & 2 & Alive & 43 \\
\hline
\end{tabular}

${ }^{a}$ EFS - Event-free survival. ${ }^{b}$ Pulmonary metastasis of a testicular primary. ${ }^{c}$ Contralateral streak ovary noted peri-operatively, SCT - sacrococcygeal teratoma.

DNA was used to analyse tumours of male and female patients, only autosomal CNIs were assessed.

\section{Statistical analysis}

Analysis was carried out in SPSS V13.0. (SPSS Inc, Chicago, IL, USA) and StatXact V4.0 (Cytel, Cambridge, MA, USA). For each chromosome arm, gains were compared to nongains (i.e. 'no change' or 'loss') and losses were compared to nonlosses (i.e. 'no change' or 'gain') using the confidence interval on the difference of two proportions. These proportions were compared between different attributes of the dataset, for example YST $v s$ germinoma, males $v s$ females, etc. The overall aim of the data analysis was to identify CNI associations worthy of further investigation. In view of this, although multiple tests were performed, associations were defined as significant where the $P$-value was less than or equal to 0.05 .

\section{RESULTS}

\section{Characteristics of childhood MGCTs analysed}

We examined 34 MGCTs from 34 different patients ( 22 female, 12 male). Of these, 33 cases were primary tumours and one was a metastasis (Table 1). There were 11 germinomas (eight dysgerminomas, two intracranial germinomas and one arising within an ovarian teratoma), 22 YSTs (eight ovarian, seven testicular, five SCT, one intracranial, one vaginal) and one EC (pulmonary metastasis from a testicular primary). Twenty-four of the primary tumours were gonadal (17 ovarian, seven testicular) and nine were extragonadal. There was one potential case of gonadal dysgenesis (case 24), where the contralateral gonad was considered to be a streak ovary intraoperatively. Otherwise no tumour included in this study was from patients diagnosed with gonadal dysgenesis (as determined by the intraoperative findings and long-term clinical follow-up). Fourteen MGCTs occurred in children less than 5 years old at diagnosis. All of these were YSTs, of which seven were testicular, five arose within a SCT, one was ovarian and one vaginal. Twenty MGCTs occurred in children 5 years or older, of which 16 were ovarian, three intracranial and one testicular. These samples included all 11 germinoma cases. The clinicopathological features of the cases analysed were largely representative of childhood MGCTs in general (Palmer et al, 2003; Schneider et al, 2004), other than a relative preponderance of ovarian samples. Seven tumours represented a single MGCT component within a teratoma and the samples analysed from these cases were completely or predominantly $(>90 \%)$ composed of the malignant element (Table 1).

\section{CNIs in the entire sample set}

The number of chromosomes showing CNIs varied from 1 to 24 per tumour (mean 9), with slightly more CNIs per YST (mean 9.5, range 1-24) than per germinoma (mean 7.1, range 2-18) (Figure 1), although the difference was not significant $(P=0.32$, Mann-Whitney $U$ test). The EC showed 17 CNIs. The numbers of CNIs are equivalent to those in previous studies (Summersgill et al, 1998; Kraggerud et al, 2000; Mostert et al, 2000; Schneider et al, 2002; Kildal et al, 2004). Commonly observed CNIs in the entire 
sample set (i.e. irrespective of histology) included gains on $1 \mathrm{q}$ (44\%), 12p (44\%), 12q (32\%), 19p (32\%), 20q (26\%), 21 (29\%) and losses on $13(26 \%)$. The most prevalent abnormality seen by us was loss on $1 \mathrm{p}$, which was detected in $20(59 \%)$ of all MGCTs and 18 $(82 \%)$ of YSTs. Less frequently, gains on $2 \mathrm{q}, 6 \mathrm{p}, 10 \mathrm{q}, 11 \mathrm{p}$ and $20 \mathrm{p}$ were observed (Figure 1).

\section{YSTs $v s$ germinomas}

YSTs were significantly more likely than germinomas to contain gains on $3 p$ and losses on $1 p$ and $6 q$, with a borderline significant increase in the frequency of loss on $4 \mathrm{q}(P=0.07)$ (Figure 2$)$. These imbalances were more typically seen in YSTs of children less than 5 (in whom the tumours were testicular) than in YSTs of children greater than 5 (in whom the tumours were typically ovarian). Germinomas showed borderline significant increases in the frequency of gain on $12 \mathrm{q}(P=0.07)$ and $19 \mathrm{q}(P=0.095)$, and loss on $11 \mathrm{q}(P=0.095)$ (Figure 2$)$.

\section{Tumour site, stage and patient age}

Of the nine extragonadal primary MGCTs analysed, three were intracranial, five sacrococcygeal (SCT) and one vaginal. The CNIs seen in these cases were equivalent to those in gonadal tumours of
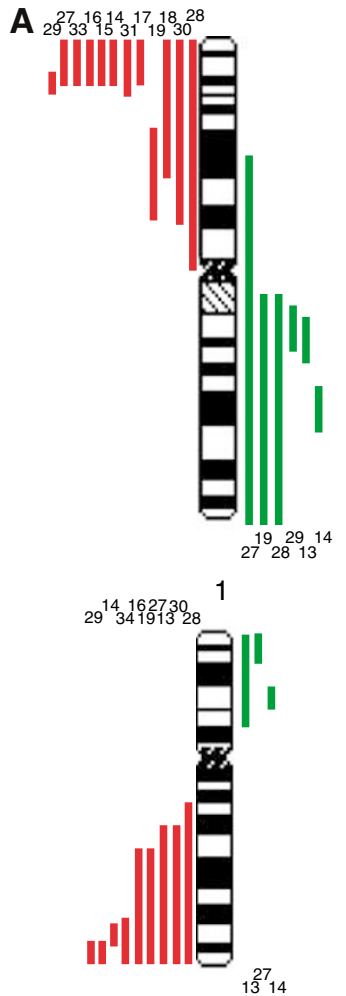

6

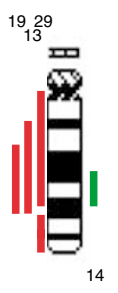

13
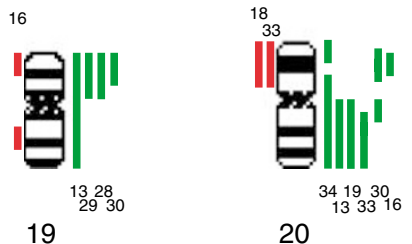

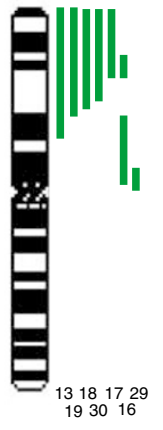

3

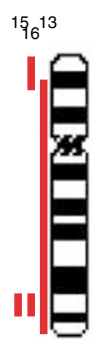

8

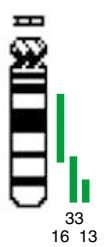

14

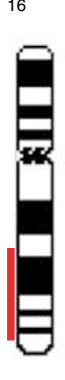

7

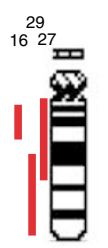

15

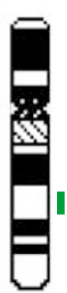

9

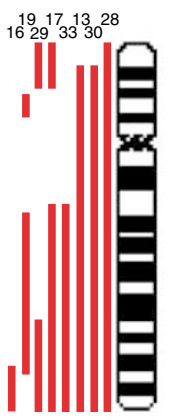

4

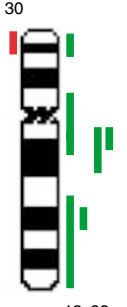

10

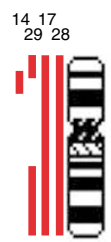

16

29

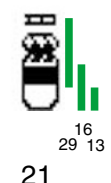

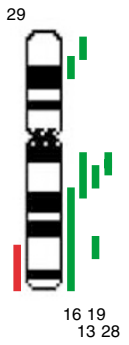

11

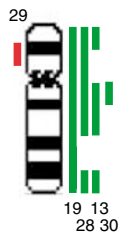

17

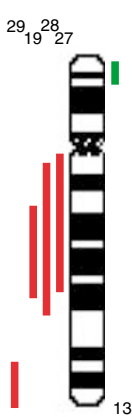

5

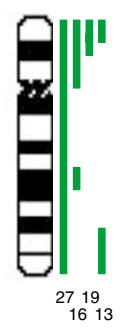

12

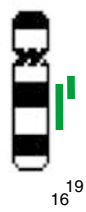

18

Figure I Summary karyograms for all 34 MGCTs analysed. Gains are shown by green bars to the right of each chromosome ideogram and losses as red bars to the left of each ideogram. Only autosomes are displayed. The numbers above or below the bars refer to individual samples. (A) Summary karyogram for all 14 MGCTs in children $<5$ years of age. (B) Summary karyogram for all 20 MGCTs in children aged $\geqslant 5 \&<16$. 

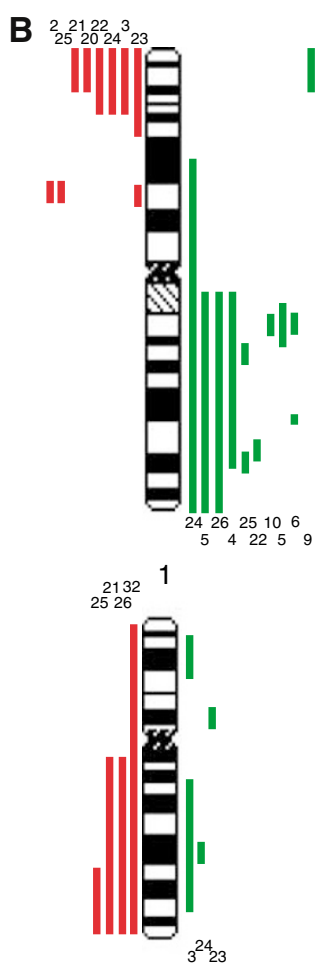

6

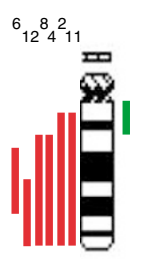

13

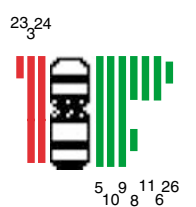

19

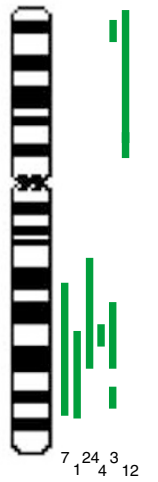

2

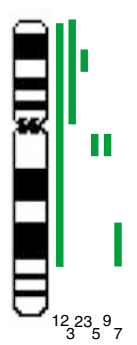

7

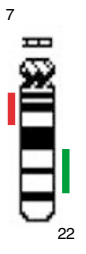

14

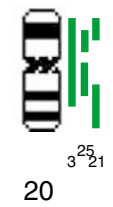

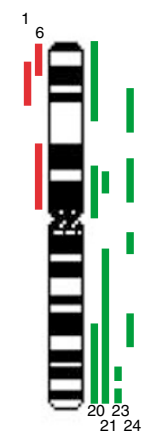

3

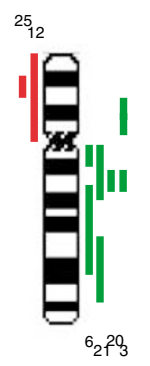

8

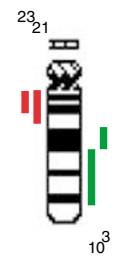

15

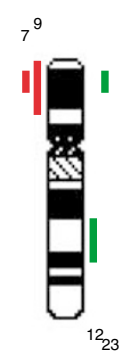

9

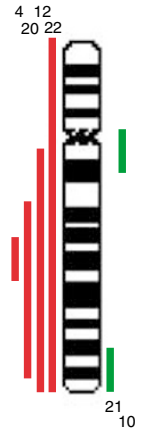

4
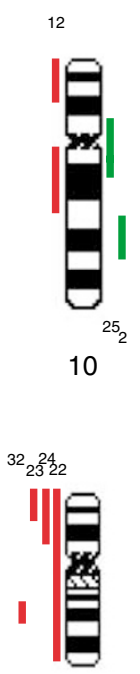

16

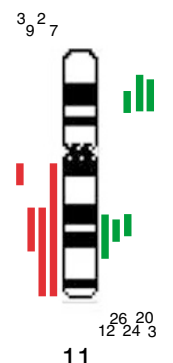

11

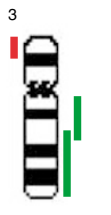

$17^{12}$

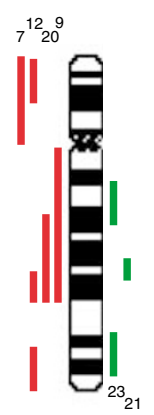

5

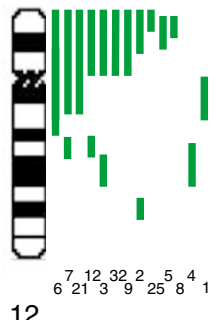

12

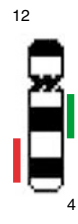

18

Figure I Continued.

similar histologies, consistent with the notion that these tumours are likely to have arisen from the same cell of origin, albeit aberrantly sited in the extragonadal cases. Testicular MGCTs, regardless of type, were more likely than ovarian MGCTs to have gain on $3 \mathrm{p}$ and loss on 8q. A greater number of CNIs per tumour was observed with increasing stage (mean CNIs of 9.2 for stage 1 and 11.7 for stage 4), although there was no evidence of an association between stage and any particular CNI. MGCTs occurring in children less than 5 years of age were more likely to contain loss on $1 \mathrm{p}, 4 \mathrm{p}, 4 \mathrm{q}$ and $6 \mathrm{q}$ compared to MGCTs in children of 5 years or more (Table 2).

\section{Chromosome 12p status}

Gain on chromosome 12p, which is invariably found in adult MGCTs (Korn et al, 1996), was observed in 15 of the $34(44 \%)$
MGCTs analysed (seven germinomas, seven YSTs and one EC). 12p gain was more prevalent in the germinomatous tumours than the YSTs, but not significantly so (64 vs $32 \% ; P=0.11)$. 12p gain was present in four of the 14 YSTs that occurred in children less than 5 years old. The regions of gain in these cases were whole chromosome 12 (case 27), 12p11-pter (case 16), 12p12-pter (case 34 ) and 12p13-pter (case 13) (Figure 3). Two of the 14 cases therefore showed gain at the $12 \mathrm{p} 11$ locus typically gained in adult MGCTs. Gain of $12 p$ was more common in children 5 or over, yet occurred in only 10 of the $19(53 \%)$ primary MGCTs in this age group. There was no evidence of a significant difference in the frequency of $12 \mathrm{p}$ gain in primary MGCTs of children aged 5 or over compared to MGCTs of children under 5 (53 vs 29\%; $P=0.19)$.

When analysing all cases combined, gain on $12 \mathrm{p}$ showed a significant association with gain of $12 \mathrm{q}(P=0.01)$, but there was no 


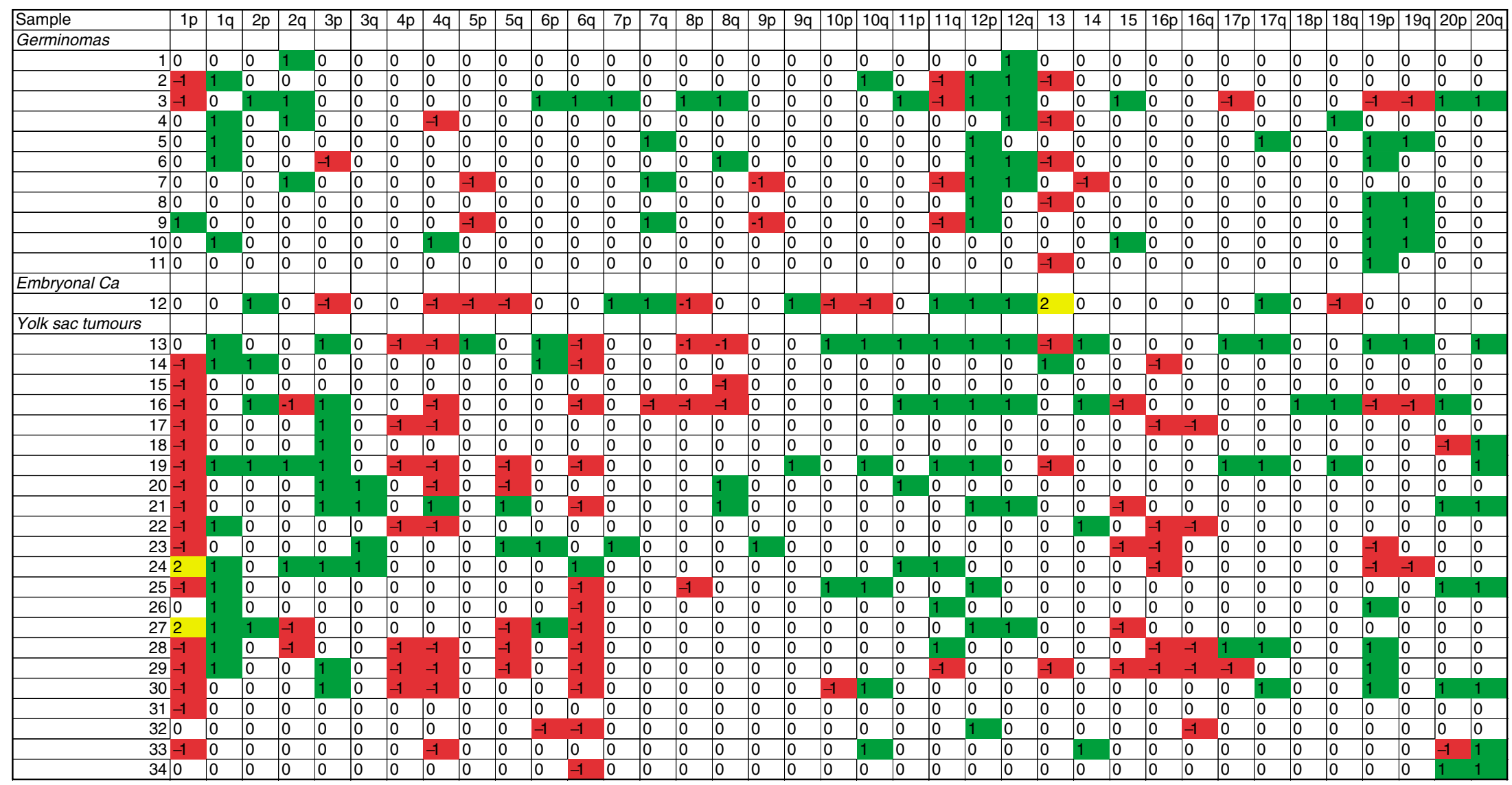

Figure 2 Summary of detectable CNls on each chromosome arm for all 34 paediatric MGCTs analysed. Gains = green, scored I; losses = red, scored - l; both gain and loss =yellow, scored 2. 
Table 2 Summary data for 33 primary MGCTs (22 YSTs \& I I Germinomas), listing those CNIs that show a statistically significant association ( $P<0.05$ ), with regard to a particular attribute. In the 'Comparison' column the numbers in brackets refer to the number of cases in the compared categories

\begin{tabular}{|c|c|c|c|c|}
\hline Comparison & Over-representation of CNI & CNI & P-value & Difference $(95 \% \mathrm{Cl})$ \\
\hline \multirow[t]{3}{*}{ Histology (germinoma vs YST) (I I vs 22) } & \multirow[t]{3}{*}{ YST } & $\mid p-$ & 0.003 & $63.6 \%[27.0 \%, 88.1 \%]$ \\
\hline & & $6 q-$ & 0.004 & $59.1 \%[21.9 \%, 82.9 \%]$ \\
\hline & & $3 p+$ & 0.02 & $45.5 \%[7.1 \%, 72.5 \%]$ \\
\hline \multirow[t]{2}{*}{ Gonadal cases (ovarian vs testicular) (17 vs 7) } & \multirow[t]{2}{*}{ Testicular tumours } & $3 p+$ & 0.02 & $53.8 \%[8.3 \%, 91.8 \%]$ \\
\hline & & $8 q-$ & 0.04 & $42.9 \%[0.2 \%, 84.8 \%]$ \\
\hline \multirow{4}{*}{ Age $(<5$ vs $\geqslant 5$ years $)(14$ vs 19$)$} & \multirow{4}{*}{ Age $<5$ years old } & $1 p-$ & 0.01 & $-43.6 \%[-76.2 \%,-9.1 \%]$ \\
\hline & & $4 q-$ & 0.02 & $-41.4 \%[-73.6 \%,-6.3 \%]$ \\
\hline & & $4 p-$ & 0.03 & $-37.6 \%[-71.3 \%,-2.6 \%]$ \\
\hline & & $6 q-$ & 0.02 & $-43.2 \%[-75.8 \%,-8.0 \%]$ \\
\hline YST cases only, age $(<5$ vs $\geqslant 5)(14$ vs 8$)$ & Age $\geqslant 5$ years old & $3 q+$ & 0.03 & $50.0 \%[6.5 \%, 87.9 \%]$ \\
\hline \multirow{2}{*}{ I 2 p gain (association with other CNIs) } & $12 p$ gain present $(n=14)$ & $12 q+$ & 0.01 & $46.6 \%[11.9 \%, 77.7 \%]$ \\
\hline & $12 p$ gain absent $(n=19)$ & $16 p-$ & 0.04 & $-36.8 \%[-67.9 \%,-3.2 \%]$ \\
\hline \multirow[t]{4}{*}{ I $2 p$ gain cases only, age $(<5$ vs $\geqslant 5)(4$ vs 10$)$} & \multirow[t]{4}{*}{ Age $<5$ years old } & $1 \mid \mathrm{q}+$ & 0.01 & $-75.0 \%[-99.8 \%,-15.9 \%]$ \\
\hline & & $6 q-$ & 0.02 & $-70.0 \%[-98.3 \%,-9.2 \%]$ \\
\hline & & $2 p+$ & 0.04 & $-65.0 \%[-99.4 \%,-3.8 \%]$ \\
\hline & & $3 p+$ & 0.04 & $-65.0 \%[-99.4 \%,-3.8 \%]$ \\
\hline \multirow[t]{3}{*}{ YST cases only, 12p gain (association with other CNIs) } & \multirow[t]{2}{*}{$12 p$ gain present $(n=7)$} & $6 q-$ & 0.009 & $60.0 \%[17.5 \%, 92.4 \%]$ \\
\hline & & $12 q+$ & 0.01 & $57.1 \%[\mid 1.0 \%, 91.7 \%]$ \\
\hline & $12 p$ gain absent $(n=15)$ & $16 p-$ & 0.04 & $-46.7 \%[-81.5 \%,-3.4 \%]$ \\
\hline
\end{tabular}

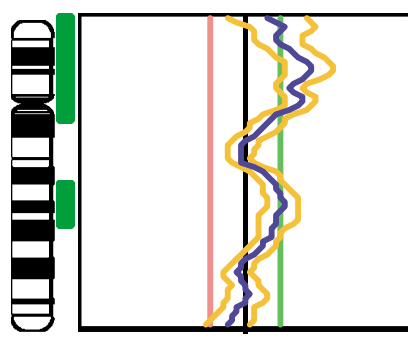

$n=27$

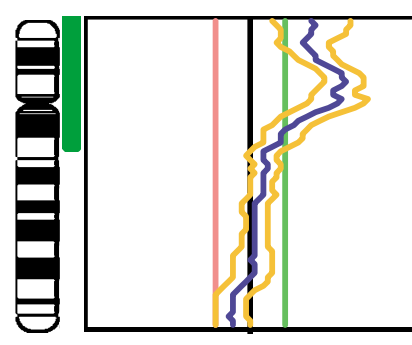

$n=31$
Figure 3 Summary fluorescent ratio profiles for chromosome 12 in two gonadal YSTs, showing the mean fluorescent ratio profile (blue line) and 95\% confidence intervals (yellow lines). The left-hand image is from a pure YST of the testis in a 4-year-old (sample 16); and the right-hand image is from a pure YST of the ovary in a 13-year-old (sample 21).

evidence of a significant association with any other CNI (Table 2). When considering only the MGCTs showing $12 \mathrm{p}$ gain, tumours in children less than 5 were significantly more likely to show gain on $2 \mathrm{p}, 3 \mathrm{p}, 11 \mathrm{q}$ and loss on $6 \mathrm{q}$ than tumours in children of 5 years or more (Table 2). In the YSTs (all ages), tumours showing $12 \mathrm{p}$ gain were significantly more likely to show loss of $6 \mathrm{q}$ and gain of $12 \mathrm{q}$ compared to tumours without $12 \mathrm{p}$ gain (Table 2).

Tumours in which $12 \mathrm{p}$ gain was absent were more likely to show $16 \mathrm{p}$ loss than samples in which $12 \mathrm{p}$ gain was present. This applied to all cases combined and also to the YSTs alone $(P=0.04$ for both) (Table 2). The smallest region of overlap on $16 \mathrm{p}$ in all cases combined was at 16p12-13.1 (Figure 1).

\section{DISCUSSION}

The 34 childhood MGCTs analysed in this study constitute the largest series so far reported and represents a substantial addition to the 82 cases published to date (see Table 3, which includes data from the present study, but excludes published cases without a CGH profile, cases reported on more than one occasion and cases where the age of the patient was not stated). We have confirmed the existence of previously recognised CNIs in MGCTs of childhood, such as losses on $1 \mathrm{p}, 4,6 \mathrm{q}$ and 13 , as well as gains on 1q, 12p, 20 and 21 (Perlman et al, 2000; Oosterhuis and Looijenga,
2005; Veltman et al, 2005). In addition, the relatively large dataset in our study has enabled us to undertake statistical investigations and thereby identify novel associations that may be relevant in the pathogenesis of childhood MGCTs.

It has previously been reported that gain of $12 \mathrm{p}$ is invariably found in adult TGCTs (Korn et al, 1996), typically as a result of iso(12p) formation. Similarly, $12 \mathrm{p}$ gain is exceedingly common in adult ovarian MGCTs (Riopel et al, 1998; Kraggerud et al, 2000). In tumours at both sites gain of 12 p11-12 (i.e. proximal 12p) is of particular importance and there is evidence for a potential role for genes in this region in the suppression of apoptosis (Zafarana et al, 2002). In contrast, gain of $12 p$ has been inconsistently reported in childhood MGCTs, with gain of 12p13-pter observed more frequently than gain of more proximal 12p (Oosterhuis and Looijenga, 2005). This has therefore formed one of the discriminatory cytogenetic features between adult and paediatric (particularly infantile) MGCTs. Interestingly, there is some evidence that $12 \mathrm{p}$ gain (whether 12p11 or whole arm) is less frequent in postpubertal childhood MGCTs than in adult MGCTs (Rickert et al, 2000; Schneider et al, 2002) (Table 3), suggesting that adolescent tumours show biological heterogeneity, which is greater than in adult MGCTs.

It was reported by Veltman et al (2005) that gain of the whole $12 p$ arm or iso(12p) has not been described in GCTs of neonates or children under 5 years old. In our series there were four cases with gain of $12 p$ in children under 5 , representing gains of whole chromosome 12 (case 27), 12p11-pter (case 16), 12p12-pter (case 34) and 12p13-pter (case 13). Furthermore, literature review indicates that 12p gain (not including isolated 12p13-pter gain) has been reported in approximately $15 \%$ of MGCTs occurring in children less than 5 years of age, whether analysed by CGH (Table 3), or kayotyping \&/or in situ hybridisation (Table 4).

It therefore appears that while $12 \mathrm{p}$ gain is less frequent in childhood MGCTs than in their adult counterparts, and less frequent in the very young than in older children, the abnormality can occur in even very young children, where it may well be of biological and clinical importance. It has been reported that 12p11.2-12.1 gain is associated with progression from carcinoma in situ to malignancy in adult TGCTs (Ottesen et al, 2003) and that a $12 \mathrm{p}$ amplicon results in more rapid progression in this setting (Looijenga et al, 1999). As the literature describes so few paediatric MGCTs, it is not known whether gain of whole arm 12p, or isolated 12p11-12.1, will confer any prognostic disadvantage in children 
Table 3 Total number of paediatric ( $\leqslant 16$ years) MGCTs analysed by CGH reported in the literature to date, with relative frequencies of gain of proximal I2p (i.e. excluding isolated 12 p 13 -pter) by age range

\begin{tabular}{|c|c|c|c|c|}
\hline & \multicolumn{2}{|c|}{ Age $<5$ years } & \multicolumn{2}{|c|}{ Age $\geqslant 5<16$ years } \\
\hline Riopel et al (1998) & I (I mixed) & I & 9 (6 DG, 2 Mixed, I YST) & $8^{\mathrm{d}}$ \\
\hline Kraggerud et al (2000) & 0 & 0 & 3 (I DG, 2 YST) & 2 \\
\hline Mostert et al (2000) & 5 (5 YST) & $3^{\mathrm{a}}$ & 0 & 0 \\
\hline Perlman et al (2000) & 16 (16 YST) & 1 & 0 & 0 \\
\hline Veltman et al (2005) & 8 (8 YST) & $1^{\mathrm{b}}$ & 3 (| DG, I YST, | Mixed) & $2^{e}$ \\
\hline Schneider et al (2006) & I (I mixed) & 0 & 9 (5 Mixed, 3 Germinoma, I YST) & $7^{f}$ \\
\hline Present study & 14 (I4 YST) & $3^{c}$ & 20 (9 DG, 8 YST, 2 Germinoma, I EC) & $9^{8}$ \\
\hline Total & 55 & $9(16.4 \%)$ & 61 & $39(63.9 \%)$ \\
\hline
\end{tabular}

Case mix includes yolk sac tumour (YST), dysgerminoma (DG), choriocarcinoma (CC), embryonal carcinoma (EC) and mixed malignant germ cell tumour (mixed). ${ }^{2} 12 \mathrm{p} \mid 2-13$ gain in all three cases. ${ }^{b}>5 \mathrm{MB}$ gain, but incomplete gain of |2p without including |2p I or |2p |3-pter. Including one case showing whole chromosome gain (case 27), and a

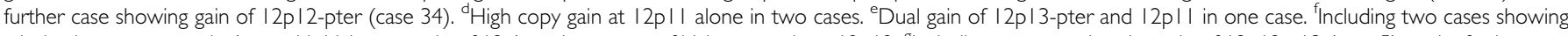
whole chromosome gain (one with high copy gain of $12 p$ ), and one case of high copy gain at $12 p \mid 2$. Including one case showing gain of $12 p \mid 2-13$ (case 5 ), and a further case showing gain of 12p 12-pter (case 2).

Table 4 Total number of paediatric ( $\leqslant 16$ years) MGCTs analysed by conventional cytogenetic techniques reported in the literature to date, with relative frequencies of iso( $12 p)$ by age range

\begin{tabular}{|c|c|c|c|c|}
\hline & \multicolumn{2}{|c|}{ Age $<5$ years } & \multicolumn{2}{|c|}{ Age $\geqslant 5<16$ years } \\
\hline Speleman et al (1990) & 0 & 0 & I (I Mixed) & I \\
\hline Shen et al (1990) & 0 & 0 & I (I Mixed) & 0 (but 4 copies of chromosome 12) \\
\hline Albrecht et al (1993) & 0 & 0 & I (I Germinoma) & 0 (but extra 12p material) \\
\hline de Bruin et al (1994) & 0 & 0 & I (I Mixed) & 1 \\
\hline Jenderny et al (1995) & $4(4$ YST) & $4^{\mathrm{a}}$ & $2(2$ YST) & $1^{a}$ \\
\hline Stock et al (1995) & 8 (6 YST, 2 EC) & 1 & 5 (2 DG, 2 Mixed, I EC) & 2 \\
\hline Sainati et al (1996) & I (I EC) & 0 & 0 & 0 \\
\hline Lemos et al (1998) & I (I Geminoma) & 0 & 0 & 0 \\
\hline Losi et al. (1994) & 0 & 0 & I (I Mixed) & I \\
\hline Bussey et al (1999) & 2I (II YST, 7 Mixed, 3 UK) & 0 & $\begin{array}{l}23 \text { (I } 6 \text { Mixed, } 3 \text { YST, } 2 \text { UK, I } \\
\text { Germinoma, I Malignant teratoma) }\end{array}$ & $\begin{array}{l}2+2 \text { other } 12 p \text { structural } \\
\text { abnormalities }\end{array}$ \\
\hline
\end{tabular}

Case mix includes mixed malignant germ cell tumour (mixed), yolk sac tumour (YST), embryonal carcinoma (EC), dysgerminoma (DG), seminoma (SE) and unknown germ cell tumour (UK). ${ }^{a}$ Gain of chromosome 12 by in situ hybridisation - iso(I2p) status unclear, but one case in each age range almost certainly iso(I2p).

with MGCTs; especially where treatment uses less toxic, carboplatin-based chemotherapy schedules. However, it is interesting that $12 \mathrm{p}$ gain was seen in both of the childhood MGCT relapses reported to date (Riopel et al, 1998; Rickert et al, 2000). In a complimentary manner, the typical cytogenetic changes of YSTs in infants (loss on $1 \mathrm{p}, 4 \mathrm{q}$ and $6 \mathrm{q}$ ) were also seen in YSTs of children over 5 years (always ovarian in this study), but with a reduced frequency. This is in keeping with published findings in pure histology YSTs affecting adolescents and adults, irrespective of tumour site (Speleman et al, 1990; de Bruin et al, 1994; Korn et al, 1996; Mostert et al, 1996; van Echten et al, 1996; Riopel et al, 1998; Summersgill et al, 1998; Kraggerud et al, 2000; Schneider et al, 2006). These findings suggest that whereas biological differences may exist between MGCTs of similar histology, distinction based simply on chronological age may not be appropriate.
We investigated which other CNIs may be important in the presence or absence of $12 \mathrm{p}$ gain in paediatric MGCTs. When analysing all cases combined, $12 \mathrm{p}$ gain was significantly associated with gain of $12 q(P=0.01)$. As gain on $12 p$ and $12 q$ may represent aneusomy for chromosome 12, it would be interesting to investigate whether cases showing both CNIs have different clinicopathological associations (e.g. histology, patient age), compared to MGCTs showing 12p gain without 12q gain. However, this exercise would require a considerably larger sample size than was available for the present study. For the tumours showing $12 \mathrm{p}$ gain, those affecting children less than 5 years of age were more likely to show gain on $2 \mathrm{p}, 3 \mathrm{p}, 11 \mathrm{q}$, and loss on $6 \mathrm{q}$, than those affecting children of 5 or more (in which $12 p$ gain may be of paramount importance). As all of the children under 5 had YSTs, this observation may reflect a feature of the tumour type (Table 2). 
Gain of $2 p$ has been reported as a relatively infrequent event in MGCTs of childhood, notably YSTs (Rickert et al, 2000; Schneider et al, 2002), but the association with $12 \mathrm{p}$ gain may be particularly relevant.

In childhood MGCTs where $12 \mathrm{p}$ gain is absent, it is likely that other CNIs are of fundamental significance. Past work has largely focused on the possibility that tumour suppressor genes exist on $1 \mathrm{p}$ or 6q, especially in infantile YSTs (Perlman et al, 2000; Hu et al, 2001), although no candidate genes have yet been identified. In our study, we discovered that in the absence of $12 p$ gain the most significant abnormality is loss of $16 \mathrm{p}(P=0.04)$, irrespective of histology. This raises the possibility that loss of one or more tumour suppressor genes on $16 \mathrm{p}$, particularly at the smallest region of overlap of $16 \mathrm{p} 12-13.1$, may be an important event in these tumours. Since many statistical tests were carried out in our analysis, it will be important first to confirm the new associations that we have discovered in an independent sample set. Nevertheless, the identification in our study of abnormalities reported by other groups lends credence to the novel associations that we have identified.

Recently, a new classification system has been proposed that separates GCTs into five types (Oosterhuis and Looijenga, 2005), where the most important discrimination in paediatric cases is between type I and II tumours. The discrimination is essentially age related, with the transition at 4-5 years, since it is rare to have dysgerminoma below this age, or testicular tumours above this age until the onset of puberty. Cytogenetically, malignant type I tumours (typically testicular YSTs in boys under 5) are reported to show gain on $1 \mathrm{q}, 12 \mathrm{p} 13$ and $20 \mathrm{q}$, as well as loss on $1 \mathrm{p}, 4$ and 6q. Type II tumours (of any histological type other than mature teratoma) have gain on chromosome 7, 8, 12p, 21 and $\mathrm{X}$, with loss of 1p, 11, 13 and 18 (Kraggerud et al, 2000; Rickert et al, 2000; Oosterhuis and Looijenga, 2005). Our study confirms that loss on $1 \mathrm{p}, 4$ and $6 \mathrm{q}$ are strongly associated with MGCTs (invariably YSTs) of children under the age of 5 years (Table 2), and therefore putative type I tumours. We also observed an increase of borderline significance in the frequency of gain on $3 p$ $(P=0.06)$ in the tumours occurring in children under 5 , which has been previously described in this age group in smaller studies (Mostert et al, 2000; Schneider et al, 2002; Veltman et al, 2005). However, we do not confirm that gain of $12 \mathrm{p}$ (specifically $12 \mathrm{p} 11$ ) is restricted to children aged 5 or over, nor to germinomatous tumours.

Furthermore, not all MGCTs in children 5 and over in our study followed the proposed type II cytogenetic profile. In comparison to the 14 MGCTs in children under 5, the 19 primary MGCTs in children of 5 or over showed minor increases in the frequency of gain on $2 \mathrm{q}, 3 \mathrm{q}, 12$ and loss on $11 \mathrm{q}$ only, with none of these differences attaining even borderline statistical significance (data not shown). Moreover, loss on 11p or 18 was not seen in any of the 19 primary tumours of children aged 5 or more and gain of $12 p$ was seen in only 10 cases (53\%). It should be noted that 16 of the 20 MGCTs of children aged 5 and over were ovarian, cases that are under-represented in the published literature.

Our findings suggest that due to the relative lack of childhood MGCTs analysed to date, the proposed classification system may rely too heavily on data from adult TGCTs. This view would be concordant with known clinical outcome data, which indicates that childhood MGCTs can be treated differently to their adult counterparts without adverse outcomes well into adolescence (Mann et al, 2000). Where the biological cut-off between childhood and adult MGCTs occurs, and what biology underpins this, has still to be elucidated. However, any new classification of GCTs needs to take these issues into account and provide robust epidemiological, biological and therapeutically beneficial information. This should be possible by integrating data produced for adult and childhood MGCTs but needs to take account of transcriptional profiles, as well as the increasing volume of available genomic and epigenetic information.

\section{ACKNOWLEDGEMENTS}

This work was funded by the Medical Research Council, Cancer Research UK, CLIC Sargent, The Parthenon Trust and Addenbrooke's Charities. DTS was supported by a Max-Eder grant from German Cancer Aid. The authors would like to thank Mr John Brown for his technical assistance with histological sectioning and staining. We would also like to express our gratitude to the CCLG, especially Kath Robinson and Professor Richard Grundy, to Dr Ian Scott for reviewing the histology, and Dr Mark Pett for reviewing the paper.

\section{REFERENCES}

Alazawi W, Pett M, Strauss S, Moseley R, Gray J, Stanley M, Coleman N (2004) Genomic imbalances in 70 snap-frozen cervical squamous intraepithelial lesions: associations with lesion grade, state of the HPV16 E2 gene and clinical outcome. Br J Cancer 91: 2063-2070, doi:10.1038/sj.bjc.6602237

Albrecht S, Armstrong DL, Mahoney DH, Cheek WR, Cooley LD (1993) Cytogenetic demonstration of gene amplification in a primary intracranial germ cell tumor. Gene Chromosome Cancer 6: 61-63

Bussey KJ, Lawce HJ, Olson SB, Arthur DC, Kalousek DK, Krailo M, Giller R, Heifetz S, Womer R, Magenis RE (1999) Chromosome abnormalities of eighty-one pediatric germ cell tumors: sex-, age-, site-, and histopatology-related differences - A Children's Cancer Group Study. Gene Chromosome Cancer 25: 134-145

de Bruin TWA, Slater RM, Defferrari R, van Kessel AD, Suijkerbuijk RF, Jansen G, de Jong B, Oosterhuis JW (1994) Isochromosome 12p-positive pineal germ cell tumor. Cancer Res 54: $1542-1544$

Foster NA, Banerjee AK, Xian J, Roberts I, Pezella F, Coleman N, Nicholson AG, Goldstraw P, George JP, Rabbitts PH (2005) Somatic genetic changes accompanying lung tumor development. Gene Chromosome Cancer 44: $65-75$, , doi: $10.1022 /$ gcc. 20223

Hu J, Schuster AE, Fritsch MK, Schneider DT, Lauer S, Perlman EJ (2001) Deletion mapping of 6q21-26 and frequency of $1 \mathrm{p} 36$ deletion in childhood endodermal tumors by microsatellite analysis. Oncogene 20: $8042-8044$
Jenderny J, Köster E, Meyer A, Borchers O, Grote W, Harms D, Jänig U (1995) Detection of chromosome aberrations in paraffin sections of seven gonadal yolk sac tumors of childhood. Hum Genet 96: 644-650

Kildal W, Kærn J, Kraggerud SM, Abeler VM, Sudbø, Tropè CG, Lothe RA, Danielsen HE (2004) Evaluation of genomic changes in a large series of malignant ovarian germ cell tumors - relation to clinicopathologic variables. Cancer Genet Cytogenet 155: 25 - 32, doi:10.1016j.cancergencyto. 2004.02.010

Korn WM, Olde Weghuis DEM, Suijkerbuijk RF, Schmidt U, Otto T, du Manior S, Geurts van Kessel A, Harstrick A, Seeber S, Becher R (1996) Detection of chromosomal DNA gains and losses in testicular germ cell tumors by comparative genomic hybridization. Gene Chromosome Cancer 17: 78-87

Kraggerud SM, Szymanska J, Abeler VM, Kærn J, Kknæs M, Heim S, Teixeira MR, Tropé CG, Peltomäki P, Lothe RA (2000) DNA copy number changes in malignant ovarian germ cell tumors. Cancer Res 60: $3025-3030$

Lemos JAR, Barbieri-Neto J, Casartelli C (1998) Primary intracranial germ cell tumors without an isochromosome 12p. Cancer Genet Cytogenet 100: $124-128$

Looijenga LHJ, de Munnik H, Oosterhuis JW (1999) A molecular model for the development of germ cell cancer. Int J Cancer 83: 809-814

Looijenga LHJ, Rosenberg C, van Gurp RJHLM, Geelen E, van EchtenArends J, de Jong B, Mostert M, Wolter Oosterhuis J (2000) Comparative 
genomic hybridization of microdissected samples from different stages in the development of a seminoma and a non-seminoma. J Pathol 191: 187 192, doi:10.1002/(SICI)1096-9896(200006)191:2 < 187::AID-PATH584 $>3.0 . \mathrm{CO} ; 2-\mathrm{T}$

Losi L, Polito P, Hagemeijer A, Buonamici L, Van de Berghe H, Dal Cin P (1994) Intracranial germ cell tumour (embryonal carcinoma with teratoma) with complex karyotype including isochromosome 12p. Virchows Arch 433: 571 - 574

Mann JR, Raafat F, Robinson J, Imeson J, Gornall P, Sokal M, Gray E, McKeever P, Hale J, Bailey S, Oakhill A (2000) The United Kingdom Children's Cancer Study Group's Second Germ Cell Tumor Study: Carboplatin, Etoposide, and Bleomycin are effective treatment for children with malignant extracranial germ cell tumors, with acceptable toxicity. J Clin Oncol 18: 3809-3818

Mostert M, Rosenberg C, Stoop H, Schuyer M, Timmer A, Oosterhuis W, Looijenga L (2000) Comparative genomic and in situ hybridization of germ cell tumors of the infantile testis. Lab Invest 80: 1055-1067

Mostert MMC, van de Pol M, Olde Weghuis D, Suijkerbuijk RF, van Kessel AG, van Echten J, Oosterhuis JW, Looijenga LHJ (1996) Comparative genomic hybridisation of the adult testis: confirmation of karyotypic findings and identification of a 12p-amplicon. Cancer Genet Cytogenet 89: $146-152$

Okada Y, Nishikawa R, Matsutani M, Louis DN (2002) Hypomethylated X chromosome gain and rare isochromosome $12 \mathrm{p}$ in diverse intracranial germ cell tumors. J Neuropathol Exp Neurol 61: 531-538

Oosterhuis JW, Castedo SMMJ, De Jong B, Seruca R, Buist J, Scharffordt Koops H, Leeuw JB (1988) Karyotyping and DNA flow cytometry of an orchidoblastoma. Cancer Genet Cytogenet 36: 7-11

Oosterhuis JW, Looijenga LHJ (2005) Testicular germ-cell tumours in a broader perspective. Nature Rev Cancer 5: 210 - 222, doi:10.1038/nrc1568

Ottesen AM, Skakkebaek NE, Lundsteen C, Leffers H, Larsen J, Rajpert-De Meyts E (2003) High-resolution comparative genomic hybridization detects extra chromosome arm 12p material in most cases of carcinoma in situ adjacent to overt germ cell tumors, but not before the invasive tumor development. Gene Chromosome Cancer 38: 117 - 125, doi:10.1002/ gcc.10244

Palmer RD, Nicholson JC, Hale JP (2003) Management of germ cell tumours in childhood. Current Paediatr 13: 213-220

Perlman EJ, Cushing B, Hawkins E, Griffin CA (1994) Cytogenetic analysis of childhood endodermal sinus tumors: a Paediatric Oncology Group Study. Pediatr Pathol 14: 695-708

Perlman EJ, Hu J, Ho D, Cushing B, Lauer S, Castleberry RP (2000) Genetic analysis of childhood endodermal sinus tumors by comparative genomic hybridization. J Pediatr Hematol Oncol 22: 100-105

Poulos C, Cheng L, Zhang S, Gersell DJ, Ulbright TM (2006) Analysis of ovarian teratomas for isochromosome 12p: evidence supporting a dual histogenetic pathway for teratomatous elements. Mod Pathol 19: 766 - 771, doi:10.1038/modpathol.3800596

Rickert CH, Simon R, Bergmann M, Dockhorn-Dworniczak B, Paulus W (2000) Comparative genomic hybridization in pineal germ cell tumors. J Neuropathol Exp Neurol 59: 815-821, doi:10.1002/10982264(2000)9999:9999 <::AID-GCC1067 > 3.0.CO;2-C

Riopel MA, Spellerberg A, Griffin CA, Perlman EJ (1998) Genetic analysis of ovarian germ cell tumors by comparative genomic hybridization. Cancer Res 58: $3105-3110$
Sainati L, Bolcato S, Montaldi A, Celli P, Stella M, Leszl A, Silvestro L, Perilongo G, Cordero di Montezemolo L, Basso G (1996) Cytogenetics of pediatric central nervous system tumors. Cancer Genet Cytogenet 91: $13-27$

Schneider DT, Calaminus G, Koch S, Teske C, Schmidt P, Haas RJ, Harms D, Göbel U (2004) Epidemiological analysis of 1,442 children and adolescents registered in the German germ cell tumor protocols. Pediatr Blood Cancer 42: 169 - 175, doi: 10.1002/pbc.10321

Schneider DT, Schuster AE, Fritsch MK, Calaminus G, Göbel U, Harms D, Lauer S, Olson T, Perlman EJ (2002) Genetic analysis of mediastinal nonseminomatous germ cell tumors in children and adolescents. Gene Chromosome Cancer 34: 115-125, doi:10.1002/ gcc. 10053

Schneider DT, Zahn S, Sievers S, Alemazkour K, Reifenberger G, Wiestler OD, Calaminus G, Göbel U, Perlman EJ (2006) Molecular genetic analysis of central nervous system germ cell tumors with comparative genomic hybridisation. Mod Pathol 19: 864-873, doi:10.1038/modpathol.3800607

Shen V, Chaparro M, Choi BH, Young R, Bernstein R (1990) Absence of isochromosome $12 \mathrm{p}$ in a pineal region malignant germ cell tumor. Cancer Genet Cytogenet 50: $153-160$

Speleman F, De Potter C, Dal Cin P, Mangelschots K, Ingelaere H, Laureys G, Benoit Y, Leroy J, Van Den Berghe H (1990) i(12p) in a malignant ovarian tumor. Cancer Genet Cytogenet 45: 45-53

Stock C, Ambros IM, Lion T, Haas OA, Zoubek A, Gardner H, Ambros PF (1994) Detection of numerical and structural chromosome abnormalities in pediatric germ cell tumors by means of interphase cytogenetics. Gene Chromosome Cancer 11: 40-50

Stock C, Ambros IM, Strehl S, Zoubek A, Fink FM, Gadner H, Ambros PF (1995) Cytogenetische aspekte pädiatrischer Keimzelltumoren. Klin Pädiatr 207: 235-241

Summersgill B, Goker H, Weber-Hall S, Huddart R, Horwich A, Shipley J (1998) Molecular cytogenetic analysis of adult testicular germ cell tumours and identification of regions of consensus copy number change. Br J Cancer 77: 305 - 313

van Echten J, Oosterhuis JW, Looijenga LHJ, van de Pol M, Wiersema J, te Meerman GJ, Koops HS, Sleijfer DT, de Jong B (1996) No recurrent abnormalities apart from $\mathrm{i}(12 \mathrm{p})$ in primary germ cell tumors of the adult testis. Gene Chromosome Cancer 14: 133-144

van Echten J, Timmer A, van der Veen AY, Molenaar WM, de Jong B (2002) Infantile and adult testicular germ cell tumors: a different pathogenesis? Cancer Genet Cytogenet 135: 57-62, doi:10:1016/S01654608(01)00643-4

Veltman I, Veltman J, Janssen I, Hulsbergen-van de Kaa C, Oosterhuis W, Schneider DT, Stoop H, Gillis A, Zahn S, Looijenga L, Göbel U, van Kessel AG (2005) Identification of recurrent chromosomal aberrations in germ cell tumors of neonates and infants using genomewide array-based comparative genomic hybridization. Gene Chromosome Cancer 43: $367-376$, doi:10.1002/gcc.20208

Zafarana G, Gillis AJM, van Gurp RJHLM, Olsson PG, Elstrodt F, Stoop H, Millán JL, Oosterhuis JW, Looijenga LHJ (2002) Coamplification of DAD-R, SOX5, and EK11 in human testicular seminomas, with specific overexpression of DAD-R, correlates with reduced levels of apoptosis and earlier clinical manifestation. Cancer Res 62: $1822-1831$ 